\title{
Arranjo e Enquadramento na Política do "E": Por Uma Pedagogia do Teatro Híbrida
}

\section{The Role of Arrangement in the Policy "E"}

Rejane Kasting Arruda ${ }^{1}$ 


\section{Resumo}

O princípio do arranjo implica a composição entre materiais externos e internos em dois eixos estruturais da ação física (horizontal e vertical), onde atuam três funções mínimas: incidência, enquadramento e vulnerabilidade. Esta estrutura pode ajudar a abrir perspectivas de investigação da poética cênica e sustentar uma "Política do E" (em detrimento da "Política do Ou"), vencendo dicotomias.

Palavras-chave: Ator; Criação Cênica; Ação Física

\section{Abstract}

The principle of arrangement implies the composition between external and internal materials in the two structural axes of physical action (horizontal and vertical), where work three minimum functions: incidence, framing and vulnerability. These structures may help to open research perspectives of the scenic poetic and to sustain a "And Policy" (to the detrimento of "Or Policy"), winning dichotomies.

Keywords: Actor; Stage Creation; Physical Action 


\section{Apresentação}

Em formação na Universidade de São Paulo, primeiramente no bacharelado em Artes Cênicas, em seguida no mestrado e doutorado na área de Formação do Ator, e trabalhando como atriz e diretora, sempre encontrei sistemas muito diferentes de Interpretação Teatral. Cada pedagogo parece fazer valer sua práxis ao explicitar uma diferença para com todos os outros. Os diferentes discursos teóricos são reafirmados ao fazerem jus a certas estéticas que (enquanto efeito destes discursos) são diferentes de todas as outras. Assim, o pedagogo (que é também diretor) faz valer seu estilo. $O$ que quero dizer é: a resultante cênica de uma improvisação a partir de pressupostos spolianos é diferente da resultante cênica constituída em um processo grotowskiano. Spolin é diferente de Barba e de Grotowski, as vezes dialoga com Stanislavski, mas, ainda assim, diverge do que chama "psicologismo". Foi a partir da minha experiência como atriz em diferentes sistemáticas do trabalho atoral, que teorizei não uma síntese, mas a perspectiva de um cruzamento, extraindo um embasamento teórico possível para o campo da Pedagogia do Teatro, através da formulação de três funções mínimas estruturais (que se repetem): enquadramento, incidência e vulnerabilidade.

Em pesquisa de doutorado na Universidade de São Paulo desenvolvi o conceito de "enquadramento" como uma organização no tempo-espaço, seja o tempo-espaço da plasticidade corporal, cênica ou da ficção trabalhada. Enquadramento é o que situa, organiza, recorta, coloca limites; enquanto "incidência" é a propriedade de afetar (sem necessariamente organizar). Ou seja, a incidência pode ser um agente do caos ou uma força contrária ao enquadramento, se opondo a este e provocando a sua dilatação. Se eu posso trabalhar com uma forma corporal específica, esta enquadra os efeitos (limita, organiza) de uma série de incidências (de imagens e palavras). Estas imagens e palavras que incidem (afetam o ator), tendem a bagunçar a forma que as enquadra, pressionando-a. Isto porque atualizam as marcas do afeto impregnadas no tecido da memória corporal. Este tecido se mexe e pressiona o enquadramento (de dentro para fora), dilatando-o, deformando-o, colocando em questão os seus limites. A esta função de atualização da memória corporal (por trazer de volta os registros antigos daquele corpo e suas grafias de afeto) chamei de "vulnerabilidade".

Esta estrutura de três funções mínimas articuladas fundamenta um processo de criação híbrido, onde se monta arranjos com diferentes materiais, utilizando-se postulados advindos de teorias diferentes que acabam por servir como instruções de jogo. Podemos criar com diferentes modalidades de enquadramento (até mesmo em oposição) e formas diferentes de material interno, abrindo então a perspectiva para a experimentação de novas produções estéticas - em diálogo com a tradição em suas diferentes vertentes (cada discurso como fonte para a extração de materiais). Assim, as diferentes práxis deixam de ser divergentes. É possível compreende-las como modalidades de jogo e configurações de arranjos diferentes; como modos específicos de articulação destas três funções (incidência, enquadramento e vulnerabilidade).

A hipótese do arranjo indica uma ética, que a justifica. Se o ator tece certa visão da personagem (com a escuta e interpretação), mas um outro (direção) introduz uma regra de jogo para que o dispositivo de atuação produza certa poética, a "política do e" nos ensina que a tensão entre os materiais conduz a uma resolução de problema 
de jogo (Spolin, 1992) criativa. O que se propõe como ética: não se elimina um material por fazer oposição a outro. Ao contrário, preserva-se as oposições em busca de uma resolução - que por sua vez será tomada como novo material. Assim, a ação física é resultante de atravessamentos (harmônicos ou dissonantes) - em um jogo. A ação física, por implicar uma organização no tempo e no espaço, se configura como enquadramento (e organiza efeitos de materiais internos que tendem a atualizar uma grafia de afetos marcada na memória corporal).

\section{O Eixo Vertical}

Esta tese implica que sempre haverá, no trabalho atoral, materiais atuando a um só tempo. Destaca-se os materiais em tensão e um jogo de enquadramento entre a plasticidade corporal e a associação com o universo ficcional que o espetador produz, enquadrando também com o seu olhar. Assim, acabamos por propor o ator como um território de atravessamentos, vulnerável a atualizações, sujeito a diferentes tipos de enquadramento, capaz de jogar com estes no momento do improviso (mesmo com uma partitura já formatada, que entra como um dos materiais no jogo).

Foi a partir deste princípio (o arranjo suporta diferentes materiais e tensões) que busquei a formalização de uma "Política do E". Isto porque sinto os atores presos a certas modalidades ou materiais - e fechados para outros que poderiam tenciona -los (criando configurações estéticas mais interessantes e produzindo poética). 0 esforço, portanto, é evidenciar que é preciso trocar a Política do "Ou" para a Política do " $E$ ", encarando os diferentes materiais como atravessamentos que levam a resoluções inesperadas e novas. Propõe-se uma arquitetura desta estrutura do trabalho do ator, com um eixo vertical onde materiais diferentes se encontram atuantes, a um só tempo (como em um acorde musical de várias notas, harmônicas ou dissonantes).

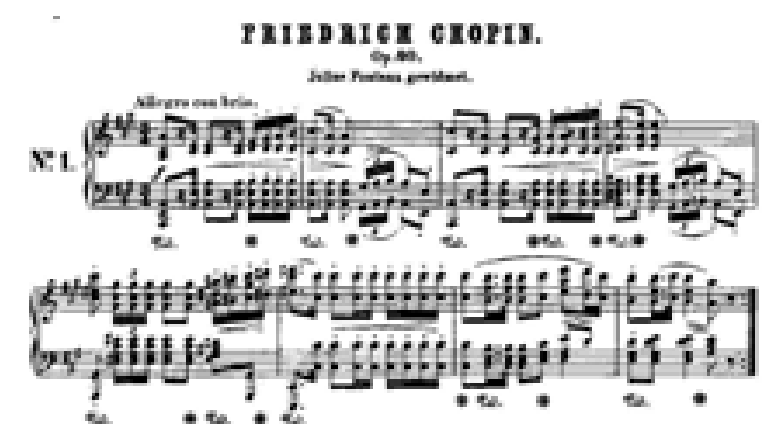

Figura 1: Pauta Musical

A verticalidade dos materiais que atuam juntos tal como notas musicais pode ser comparada ao eixo vertical da estrutura da linguagem proposto por Saussure. Os significantes (elementos diferenciais) estão empilhados, ao contrário do que acontece no eixo horizontal (onde se encontram sequenciados) ${ }^{2}$. O eixo vertical da linguagem, é um eixo de "possíveis", "presentes na ausência", e implica uma operação chamada de "condensação": síntese, relação dialética, coexistência de diferentes. Esta ideia 
aponta para a complexidade do arranjo atoral, com resíduos de materiais antigos ou "presentes na ausência", materiais que não estão diante dos olhos ou na escuta, mas presentes somente enquanto eco ou reverberação do passado impregnado no corpo. Através desta ideia é possível aprofundar a analogia com as notas musicais. Se a um só tempo, no eixo vertical, os materiais formam acordes (como já foi dito), no eixo horizontal formariam melodias - organização temporal, enquadramento. Assim, o eixo vertical seria o eixo da incidência e o eixo horizontal, do enquadramento.

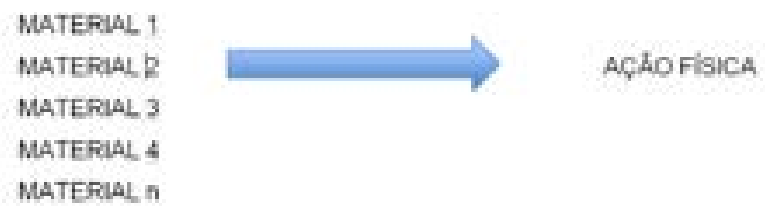

Figura 2: Eixo Vertical: Empilhamento de Materiais

A função do arranjo implica um trabalho com diferentes modalidades de material (palavra, objeto, som, imagem, movimento) a um só tempo. Estes materiais exercem sobre o ator a excitabilidade. É o que, em última instância, define uma escolha (em detrimento de outras): o que causa excitabilidade (em outras palavras, o que incide).

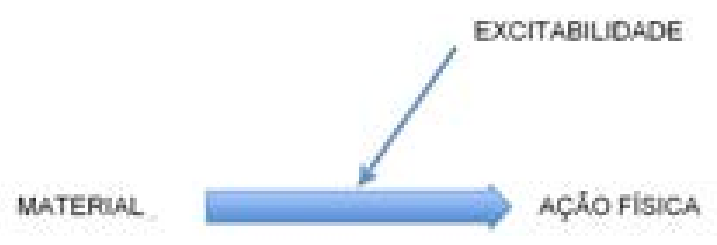

Figura 3: Excitabilidade

\section{A Ação Física como Material de Enquadramento}

A ideia de jogo norteia toda atividade cênica. As ações físicas podem e devem ser tomadas como resultantes de um jogo na medida em que $o$ ator resolve problemas (Spolin, 1992) - ou como materiais em jogo, na medida em que fazem parte de um arranjo complexo que as ultrapassa. Ao fazer valer o princípio do jogo como fundamento, podemos afirmar que a partitura física ou ação física entra em jogo com materiais internos que tendem a deforma-las, implicando "resolução de problema" (Spolin, 1992) criativa. Como material de enquadramento, a ação física é passível de transformação. A utilização da música, do objeto, da palavra externa ou da palavra interna a transforma (tem plasticidade), criando um outro enquadramento. Quando a forma da ação física original é deformada, ela evocará um outro contexto (que também acaba por exercer a função de enquadramento). Quando sua forma se repete, 
ainda assim é diferente da anterior, pois implicada em um arranjo que conta com uma série de contingências.

Pode-se dizer que, para Grotowski. a ação física é uma junção de materiais internos (que ele chama de baterias psíquicas) e externos (partiturização detalhada do corpo, organização, enquadramento), sem que evoque a cotidianidade (que considera banal) ou estereótipos gestuais (que se revelam como superficiais, formas socialmente banalizadas). Grotowski procurava novas formas, que pudessem se remeter ao corpo-memória, à herança de um corpo pulsional, afetado por paixões, entrelaçado a forças ancestrais. Assim, propôs ações físicas nascendo "de dentro para fora", afirmando sua diferença em relação a Stanislavski (que, a partir do Método de Ações Físicas, teria proposto o caminho inverso, "de fora para dentro").

A ação física em Stanislavski no entanto é uma organização externa que ainda precisa ser transformada em "ação psicofísica". Ela implica a cotidianidade - quando se propõe a mimese do cotidiano evocado pelo texto dramático (o que se revela como modalidade específica de enquadramento). Palavras que o ator inventa com narrativas subjacentes à obra dramatúrgica trabalhada, criando subtexto (pois "o subtexto", como diz Stanislavski, "é do ator") produz imagens. Os procedimentos stanislavskianos indicam a existência de uma rede verbal de materiais situando um imaginário, causando excitabilidade e incidindo sobre as ações físicas. É porque a palavra externa (dita em cena e extraída do texto dramático) provoca a atualização de marcas corporais impregnadas na tessitura corporal, que outros enquadramentos são necessários; provocando relação, tensão e atualizações, deixando a produção corporal mais complexa e ambígua.

Já em Barba, chama-se de ação física as ações de empurrar, lançar e puxar (utilizadas nos treinamentos físicos). Estas ações promovem enquadramento plásticocorporal abstrato. O sentido da ação é descoberto a posteriori na medida em que um outro enquadramento é visualizado: uma relação ou um contexto para estas formas. Outras vezes preserva-se a abstração, perdendo-se a necessidade de um contexto e afirmando o agente da criação como um "ator-bailarino". Barba defende a abstração e traz apontamentos importantes quando relê Stanislavski e destaca o caráter puramente rítmico de suas construções, a descolando de um contexto ficcional ou situação. Ou seja, percebe-se que as diversas noções de ação física implicam modalidades diferentes de enquadramento.

\section{Dois "Dentros"}

Também a fala interna (Kusnet, 1992) ou monólogo interior (Knebel, 2002), a substituição (Hagen, 2005) e a visualização transformam uma ação física, se apresentando como materiais na composição do arranjo. Pode-se alterar radicalmente ou sutilmente a ação física ou movimento que, absorvido por outros enquadramentos, se transforma. A resultante será diferente se o ator trabalhar a mesma partitura física com outra música, narrativa subjacente, imaginário, detalhe imaginativo, etc. A par- 
titura física é um enquadramento espacial que se transforma conforme o arranjo 3 . Chamamos este princípio de "Jogo de Enquadramentos".

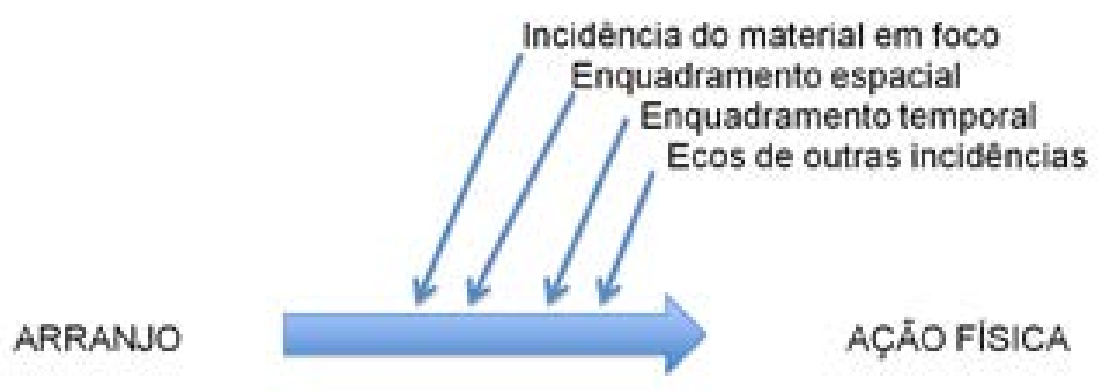

Figura 4: Jogo de Enquadramentos

A fala interna é um conceito-chave. Propriamente, trata-se da escuta como função, pois a palavra não está exposta na realidade objetiva (não se ouve de fato). A fala interna é a escuta de frases que não estão projetadas na cena. Podemos dizer que é escuta de pensamento - pensamento enquanto estrutura verbal que pode ser repetida. A fala interna pode ser de diferentes modalidades: uma instrução de jogo (ecoando escondida) ou o pensamento da personagem. Quando Stanislavski pergunta ao ator o que faria se fosse a personagem, configura uma modalidade possível de fala interna, porque há produção de palavras que não serão ditas em cena, mas reverberam (produzem incidência). Existe um lugar estrutural a ser ocupado pela fala interna, de escuta, que o ator maneja.

Kusnet utiliza uma estratégia: escreve as conversas consigo mesmo. O que Stanislavski chamou de "Monólogo Interior" é, na verdade, um diálogo segredado e resmungado: "Não devo! Mas por quê? Ah não! Devo sim! Vamos lá! Coragem!" Kusnet propõe que o ator o mentalize (escute) e o reduza para uma frase: "É agora!". Esta seria a modalidade de fala interna kusnetiana: a redução do monólogo interior.

Enquanto o ator improvisa com elementos externos (as bordas do seu corpo), a fala interna situa (ou divide) o seu foco de atenção, criando reverberações, que são, por sua vez, enquadradas pelas bordas corporais. Assim, a clássica ideia da emoção como um "dentro" oposto ao "fora" (ação física) se dilui. Existe algo "dentro", que se pode perfeitamente manejar e montar com a ação física: imagens visuais e acústicas (fala interna).

Contemporaneamente se postula o Método de Ações Físicas como a grande virada do Sistema. Em certo momento, Stanislavski diz que o ator deve focar na ação física, pois emoções são escorregadias: "Não me falem de sentimentos, não podemos fixar os sentimentos. Podemos fixar e recordar somente as ações físicas" (Stanislavski apud Toporkov, 2004, p. 111) ${ }^{4}$.

Houve um momento em que Stanislavski dialogou com Pavlov e James. Última palavra da psicologia na Rússia e nos EUA, estes autores influenciaram também

3 A partitura pode ter dinâmica rítmica própria (ou tempo-ritmo, como dizia Stanislavski), de maneira a ser também enquadramento temporal. 4 Don't talk tome about feeling, you cannot set feeling. You can only recall and set physical action (Stanislavski apud Toporkov, 2004, p. 111). 
Meyerhold. É de William James a proposição de que uma ação provoca a emoção. Sua marca registrada é a frase "Vejo o urso, corro e sinto medo" (nesta ordem). Quanto a Pavlov, formulou a teoria da reflexologia: um cão passa a salivar quando escuta a campainha que está associada à presença da comida (e a antecipa). O interesse de Pavlov estava no aprendizado e as suas relações com recompensa e castigo. Esta teoria foi chamada behavorismo (behave é comportamento) ${ }^{5}$. No entanto, contemporaneamente e com novo pensamento, pode-se formular que está em jogo uma operação da linguagem (de substituição), uma metáfora: a campainha no lugar da comida.

Ao defender que o ator deve focar na ação física, Stanislavski não deixou o uso das frases ocultas (internas); não abandonou a produção verbal estimulada com perguntas: "Quando Stanislavski trabalhava sobre as ações físicas, superou, mas também prolongou, a sua velha ideia de "memória emotiva". Perguntava ao ator: 'o que você faria, se estivesse nas circunstâncias dadas?" (Grotowski, 1993, p. 16). Trata-se de uma das maneiras possíveis de se produzir materiais internos. Existem formas diversas de criação de material interno. Grotowski, por exemplo, interessado no corpomemória, utiliza uma modalidade diferente.

Quando eu trabalhava com um ator, não refletia nem sobre o 'se' nem as 'circunstâncias dadas'. Existem pretextos ou trampolins que criam o evento espetacular. $\mathrm{O}$ ator apela para a própria vida, não procura no campo da "memória emotiva", nem do "se". Dirige-se ao corpo-memória, não à memória do corpo, mas justamente ao corpo-memória. E ao corpo-vida. Então se dirige para as experiências que foram para ele verdadeiramente importantes ou para aquelas que ainda esperamos, que não vieram ainda. Às vezes a recordação de um instante, um único instante, ou um ciclo de recordações em que algo permanece imutável. Por exemplo, a recordação de uma situação-chave a respeito de uma mulher. (Grotowski, 1993, p. 16)

A "política do E" implica que o ator pode experimentar modalidades diferentes em arranjos diversos, trazendo uma perspectiva de investigação de poéticas resultantes conforme o arranjo. Percebe-se a existência de um "dentro" confiável que não é a emoção, mas imagens visuais (que Kusnet chama "visualização") e acústicas (verbo). Estas são passíveis de repetição e compostas com os desenhos corporais: enquadramentos espaço-temporal ("fora"). A função do arranjo implica que a ação física se dá por composição entre dentro e fora. O ator deve borrar "o fora" enquanto "o dentro" faz incidência, suscitado por associações também a partir de um fora. Se o enquadramento determina limites, nele esbarram as reverberações do interior do corpo, tessitura de memória que ressona. Nesta tessitura, existem marcas que reaparecem, pressionando as bordas do enquadramento (partitura pré-determinada, limite espacial, relação com regras de jogo, etc.). Percebe-se algo que se move dentro da

\footnotetext{
5 Ver mais em: Stephenson, Graham. Stanislavski and Postmodernism. Thesis submitted to ghoe University of Birmingham For the degree of MPHIL (B). Disponível em: http://etheses.bham.ac.uk/3321/1/Stephenson12MPhil.pdf Acesso em 02/01/2015. Também: OLIVEIRA, Ângela. Fluxo de Consciência, Psicologia, Literatura, Teatro: Um Início de Conversa. Revista Cena em Movimento, N. 1. Disponível em: http://seer.ufrgs.br/cenamov/article/view/21605 Acesso em 02/01/2015. E ainda: ARAKI, Mauro. Filosofia e Psicologia em William James. Dissertação paresentada ao Programa de Pós-graduação em Filosofia da Universidade de São Carlos como parte dos requisites para a obtenção do título de Mestre em Filosofia. Disponível em: http://www.bdtd.ufscar.br/htdocs/tedeSimplificado//tde_busca/ arquivo.php?codArquivo=2428 Acesso em: 02/01/2015. KINOUCHI, Renato. Tão perto, tão distante: William James e a psicologia contemporânea. São Paulo: Scientiae Studia, v.7, n. 2, p. 309-15, 2009. Disponível em: http://www.scielo.br/scielo.php?pid=S1678-31662009000200009\&script=sci_arttext. Acesso em: 02/01/2015. PAPAGEORGOPOULOS, Panagiotis. The Lamenting Brain: Emotion, Action and the Journey of Feelings in the Actor's Mournful Art. Department of Drama and Theatre Royal Holloway College University of London. Submission for the degree of Doctor of Philosophy, 2009. Disponivel em: https://repository. royalholloway.ac.uk/file/d12e0c96-c647-99bd-018e-f730465b0c11/9/2010PapageorgopoulosPPhD.pdf. Acesso em: 02/01/2015.
} 
tessitura corporal, revelando-se interna (um outro "dentro" portanto). Esta área de atualização advogamos como um "dentro" de onde surgem impulsos (relacionando -o ao corpo-memória grotowskiano).

Mas o fato de o testemunharmos, não nos impede de também testemunhar aquela escuta de materiais acústicos e visuais como um primeiro "dentro", estes materiais que Stanislavski aciona quando faz perguntas ao provocar respostas (produção verbal e visual). Também não nos impede de testemunhar que o "fora", a produção corporal (seja de si ou do outro), retorna a um só tempo sobre o olhar e escuta do ator através de associações cuja incidência se faz sentir. Temos uma dobra, portanto. A figura representativa do entrelaçamento das três funções passa a ser a garrafa de Klein.

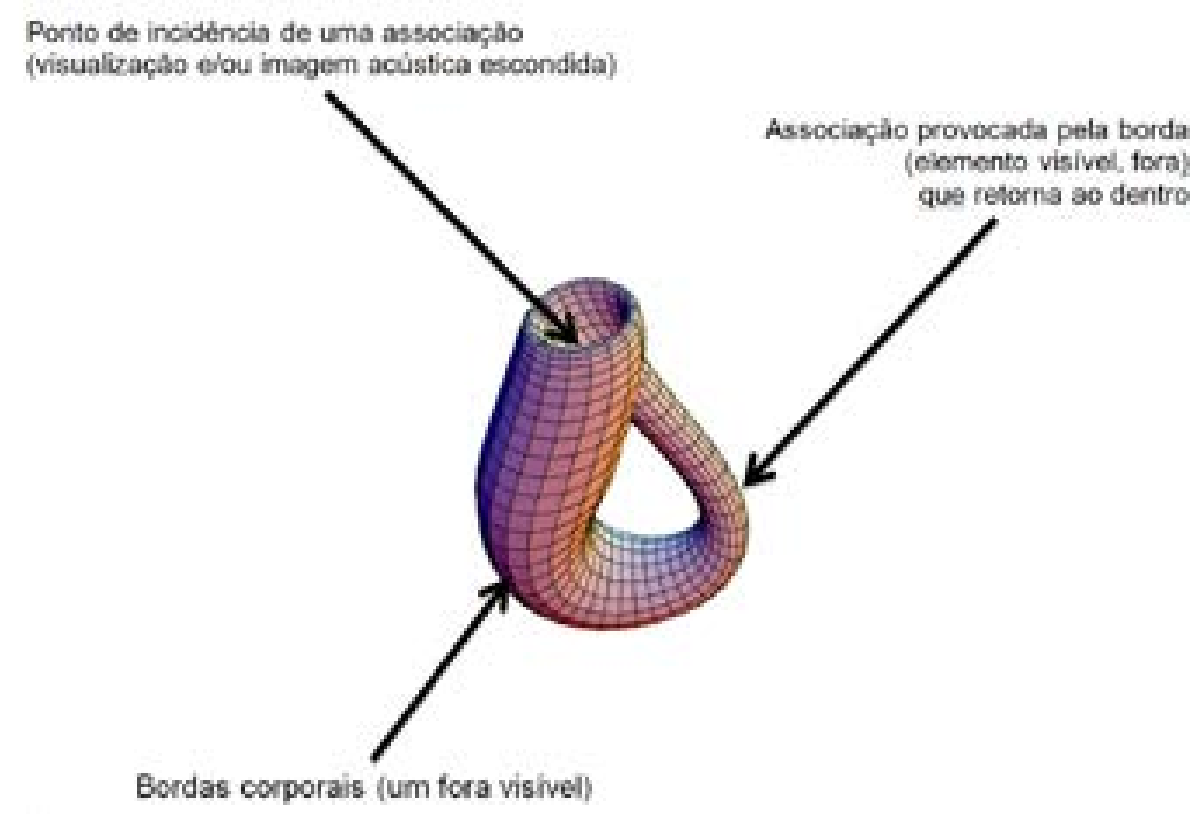

Figura 5: Estrutura da Ação Física (Garrafa de Klein)

\section{A Fala Interna como Material de Enquadramento ou Incidência}

Se uma fala interna ocupa o tempo, é também material de enquadramento. Levando um tempo para ser pensada (ou escutada), para se desenrolar na escuta, ela condiciona uma pausa. Mas a fala interna pode não ocupar o tempo - de forma a não funcionar como um enquadramento. Não estando organizada em um eixo horizontal (da sucessão), mas "em pé" (naquele eixo vertical que nos lembra o acorde de notas musicais), aparece como o significante saussuriano: "presente na ausência". Não ocupa o tempo cronológico. Cedendo lugar a outras palavras que a substituíram, é passado e memória. Mantendo-se na teia da linguagem que atravessa o sujeito com os seus ecos, sua reverberação está impregnada na tessitura corporal. Um ator pode concentrar toda a energia para escutar as falas internas que compõem o seu monólogo interior em cena. Neste caso, este funcionará como um elemento de enquadramento (enquadramento interno). Fala interna e monólogo interior servem para construir ações internas, enquanto o desenho corporal se organiza. A ação interna pode se opor à externa. Era isto que Kusnet defendia como "contradição da 
personagem", conquistada a partir da oposição entre materiais internos e externos. É como pensar "eu te amo" e falar "eu te odeio": a resultante implica a composição entre o dentro e o fora.

Assim, o problema "de dentro para fora ou de fora para dentro" se dilui. O que existe é a composição de dentro e fora (materiais que podem se opor e podem ser múltiplos). O desenho corporal (casca, linha, grafia) suscita associações (imagens acústica ou visuais), acionando o interno e fazendo reverberar uma tessitura do corpo que, permeada de afetos, preenche e pressiona o desenho (as bordas), dilatando-o. Por outro lado, o material interno (visualização e/ou fala interna, associação, memória e/ou fantasia) provoca a tessitura corporal produzindo uma forma (atualizando um repertório de desenhos corporais que a tessitura de memória corporal já guardou). Estes materiais podem ser planejamos ou associados sem querer durante o jogo ou cena.

\section{Jogo entre Plasticidade Cênica e Contexto Diegético}

A teoria do arranjo se desdobra no jogo de enquadramentos. Por exemplo, o jogo entre um imaginário sobre a ficção (a personagem e as relações diegéticas) e ações físicas (postas em cena). São dois enquadramentos diferentes: um é o plásticocorporal no tempo-espaço, o outro é a evocação da lógica imaginária de uma ficção. O contexto das relações, o contexto do cotidiano da ficção, o sentido e a lógica de um "ser ficcional" (personagem), podem organizar, situar, justificar (Knebel, 2002) a ação física através do contexto diegético. O elemento ficcional (a ação dramática, da personagem) possui uma visualidade que enquadra (organiza) a ação física (que é puro desenho cênico), a situando no interior das relações ficcionais.

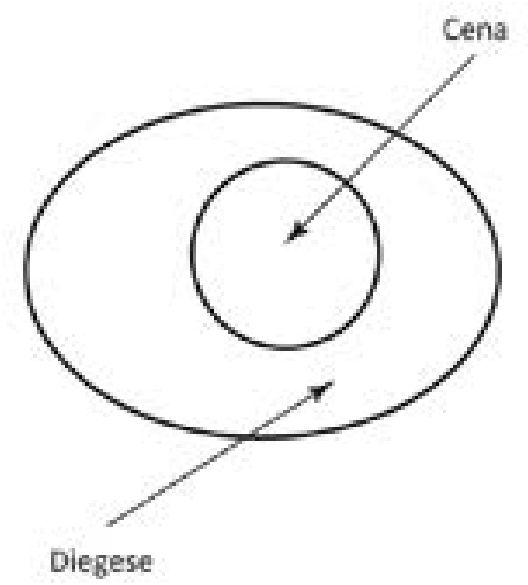

Figura 6: Jogo de Enquadramento entre Contexto Cênico e Diegético

Ao dizer que atividades não são ações físicas, Grotowski acaba por revelar o enquadramento através de uma narrativa, com direito à relação com outro e o tempo da causalidade (com uma coisa depois da outra) - quando se trata de ação física.

[...] a atividade pode se transformar em ação física. Por exemplo, se vocês me colocarem uma pergunta muito embaraçosa, que é quase sempre a regra, eu tenho 
que ganhar tempo. Começo então a preparar meu cachimbo de maneira muito "sólida". Neste momento vira ação física, porque isto me serve neste momento. Estou realmente muito ocupado em preparar o cachimbo, acender o fogo, assim DEPOIS posso responder à pergunta. (Grotowski, 1968, p. 01)

Quando se trata de ação física está implicado um enquadramento imaginário, o sentido de uma ação de "acender o cachimbo" através da relação com o outro. No caso do contexto dramático (implicando um "quem, onde e o quê" ficcionais) existe o tempo-espaço das relações inventadas (evocadas) para enquadrar as ações físicas nas ações dramáticas. A função de um imaginário sobre a personagem é a mesma de uma fala interna ou de uma música: transformar o que poderia ser uma abstração (linha, traço, desenho) corporal em ação física. Grotowski diferencia a ação física também do gesto e do movimento.

$\mathrm{O}$ ator que representa Romeu de maneira banal fará um gesto amoroso, mas o verdadeiro Romeu vai procurar outra coisa; de fora pode dar a impressão de ser a mesma coisa, mas é completamente diferente. Através da pesquisa dessa coisa quente, existe como que uma ponte, um canal entre dois seres, que não é mais físico. Neste momento Julieta é amante ou talvez uma mãe [...]. Vejam a mesma coisa com o cachimbo, que por si só é banal, transformando-a a partir do interior, através da intenção - nesta ponte viva, e a ação física não é mais um gesto (Grotowski, 1968, p. 01-02).

Estas diferenças são importantes para o trabalho atoral. Pode-se partir de um movimento abstrato e o transformar em ação física a partir da incidência de outro enquadramento ou fala interna. Assim, descobre-se o sentido da ação em cena, no jogo, na improvisação. É possível exercitar toda uma gama de transformações: um gesto para uma ação física; um movimento para uma ação física; uma atividade para uma ação física; uma ação física para outra. O enquadramento abstrato, contaminado pela relação com o outro, é deformado, e surge outro enquadramento: a ação física resultante deste jogo. Alterando a primeira forma, chega-se à forma da ação final - com circunstâncias, narrativa, fala interna, visualização, etc. Os dois enquadramentos (plástico-corporal e ficcional) se compõem para que a ação física surja. De maneira que o ator utiliza tanto materiais internos quanto externos e modalidades (tipos) de cada um deles em um jogo de construção complexo. Tal como no arranjo musical, dependendo da presença de várias notas (e não de uma apenas) para gerar harmonia ou dissonâncias.

\section{Conclusão}

Se existe um vetor que vai de um arranjo de materiais até uma ação física resultante, acreditamos que: a). são muitos os materiais (e não um) para gerar a mesma ação física; b.) o "dentro" e o "fora" se encontram; c.) o "dentro" pode ser situado com precisão através de imagens e/ou palavras que só o ator escuta e olha (internas); d.) o uso de materiais implica ressonâncias e afetos na memória corporal; e.) as reverberações podem retornar em uma área de vulnerabilidade do corpo (que é transpassado por linguagem, memória, afeto e experiência); f.) cria-se um espaço de reverberação da memoria corporal e sua grafia de afetos, atualizando formas que pressionam os enquadramentos. 
MATERIAIS

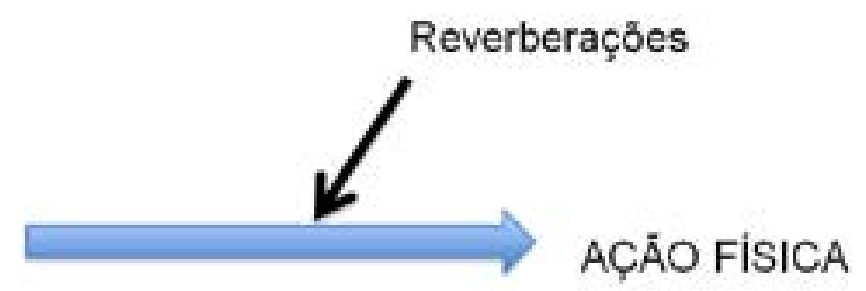

Figura 7: A Memória Atualiza Reverberações

\section{Referências}

ABENSOUR, Gérard. Vsevold Meierhold ou A Invenção da Encenação. São Paulo: Perspectiva, 2011.

GROTOWSKI, Jerzy. Respuesta a Stanislavski. Máscara - Cuaderno lberamericano de Reflexion sobre Esconologia (Grotowski), México, año 3, n. 11-12. p. 18-26, 1993.

GROTOWSKI, Jerzy. Sobre o Método das Ações Físicas. Palestra no Festival de Teatro de Santo Arcangelo (Itália), jun. 1988. Disponível em: http://www.grupotempo.com. br/tex_grot.html Acesso em 02. Jan. 2015.

KNÉBEL, María. La Poética de la Pedagogía Teatral. México: Siglo XXI, 2002.

KUSNET, Eugenio. Ator e Método. São Paulo: Hucitec, 1992.

PAVIS, Patrice. Dicionário de Teatro. São Paulo: Perspectiva, 1999.

PICON-VALLIN, Béatrice. A música no jogo do ator meyerholdiano. In: Le jeu de l'actor chez Meyerhold et Vakhtangov, Paris, T. III, p. 35-56, 1989. Tradução: Roberto Mallet. Disponível em: http:// www.grupotempo.com.br/tex_musmeyer.html. Acesso em: 02 jan. 2015.

SAUSURRE, Ferdinand. Curso de Linguística Geral. São Paulo: Cultrix, 2006

SPOLIN, Viola. Improvisação para o Teatro. São Paulo: Perspectiva, 1992.

STANISLAVSKI, Constantin. A Criação de Um Papel. Rio de Janeiro: Civilização Brasileira, 2005.

STANISLAVSKI, Constantin. A Construção da Personagem. Rio de Janeiro: Civilização Brasileira, 1970. 
STANISLAVSKI, Konstantin. A Preparação do Ator. 15a ed. Rio de Janeiro: Civilização Brasileira, 1999.

TOPORKOV, Vasili. Stanislavski in Rehearsal. New York: Routledge, 2004

Recebido em: 02/01/2016

Aprovado em: 16/04/2016 